\title{
AMI learning - an interactive multimedia application for learning in maritime and inland waterway radiocommunication training programmes
}

\author{
Vasile PIPIRIGEANU ${ }^{1, a}$ \\ ${ }^{1}$ Romanian Maritime Training Centre-CERONAV, Romania \\ avasilepipirigeanu@ceronav.ro
}

Keywords: interactivity, platform, multimedia, maritime, radio communication, learning, competence based training, assessment.

\begin{abstract}
This article introduces an interactive multimedia application used for GMDSS training in the Romanian Maritime Training Centre - CERONAV by maritime/ river officers and cadets. The application actually covers the theoretical, introductory part as well as the assessment of theoretical knowledge as additional tool to the practical training in the simulator and demonstrates how an interactive platform supports the practical training to achieve the required competences for the radio operators' job. The content of application could be very easily updated by instructors and trainees.
\end{abstract}

\section{Introduction}

Safety is one of the main concerns of the International Maritime Organization - IMO [1]. In this context, a new mandatory system of maritime radio communication on board ships was introduced starting with 1999: Global Maritime Distress and Safety System, GMDSS.

Beyond the pros and cons of the debates regarding the e-learning and computer based learning/ Information and Communication Technology, the technological evolution requires continuous adjustment to the needs of the information recipient. We cannot speak about complete removal of face-to-face training but probably the future will enforce a mixture of traditional methods, electronic ones and practical training. In the last period, there has been a continuous increase of education activities using technology to support the active process of learning.

In the maritime sector IMO requires the acquisition of skills that can be achieved through specific training programmes, so we must shift from an educational system based on the accumulation of relevant knowledge to one based on competences. This involves, besides accumulation of theoretical knowledge, a combination with practical training on real or simulated equipments. Modern technologies provide interactive activities which are necessary especially in training systems based on the acquisition of skills and by using simulation we could reduce the cost of qualification process versus training on real equipments.

\section{Description of the created application}

The IMO STCW Convention establishes the internationally acceptable minimum standards of training and certification for crews [1]. There are a lot of rules for operating the GMDSS equipments and other maritime operational procedures that any radio operator shall learn and demonstrate, theoretically and practically [2]. For inland waterway (the Danube region) the equipments are the same and there are many concerns for similar standardization as in maritime field. Two European projects called HINT and NELI contribute to the harmonization process of education and training standards, adoption and development of digital tools and teaching materials for inland waterways. [3], [4].

In the context of competence based training, learning becomes a more individualized process, more personal oriented and self managed. There are many software applications or simulators on the market but these are very expensive and not so easy to use in a usual classroom [5]. 
In this context I have created an interactive application called AMI (Interactive Multimedia Application) for learning in radio communication programmes. The platform is created on HTML support with configuration and database in XML format. The programming was made in Visual Basic (Visual Studio Package) and allows easy updating of content. The instructor could modify different sections by adding/ deleting, pages, new sections, questions, PowerPoint slides, tables, text, images. These operations are very easy to execute by anyone without programming skills using a simple text editor by accessing separate sections created for images ("photo viewer"), text ("html viewer"), PowerPoint slides ("ppt viewer"), video files ("video viewer") and self assessment ("test viewer"). The algorithm of the application it is presents in Fig. 1.

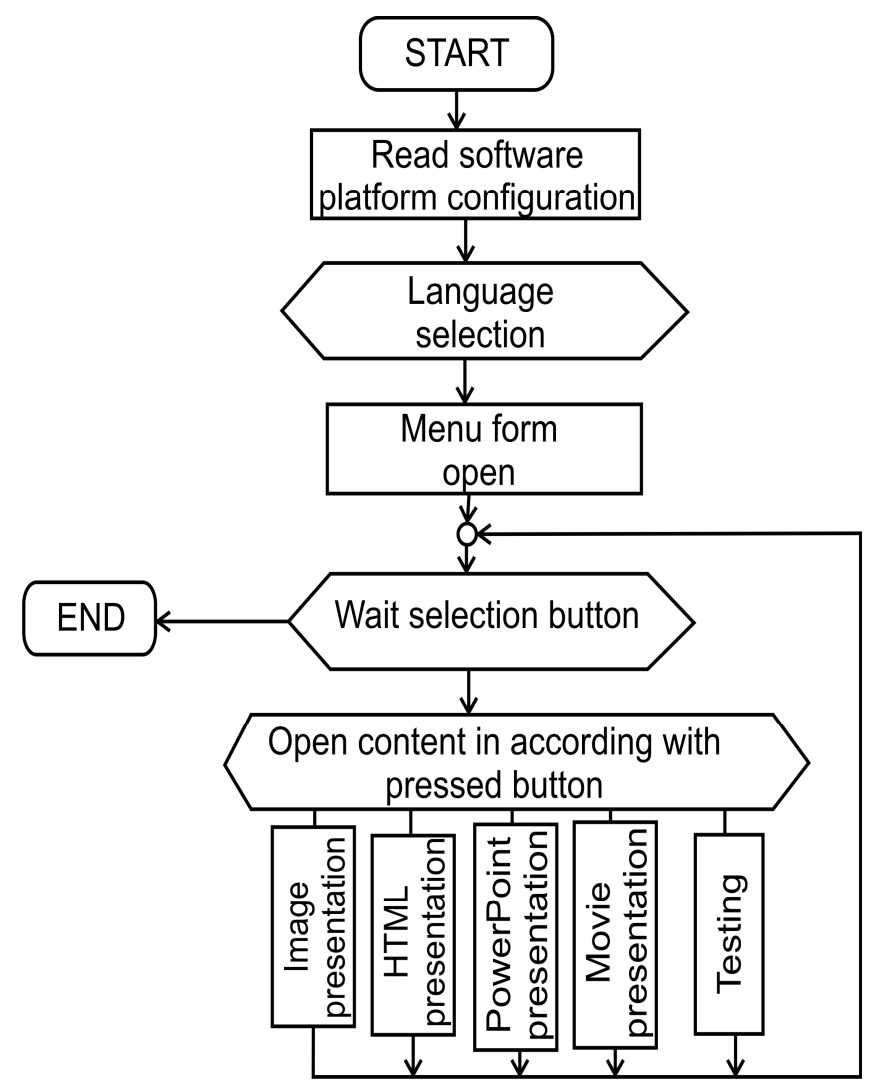

Fig. 1 AMI algorithm

The AMI Learning also includes a Glossary (more than 250 terms) and Useful links sections that could be used anytime during the learning process. Also these two sections could be modified by changing or adding new information.

Designed as an aid in training programmes, the application includes a section for self assessment of knowledge. It was built as a "multiple choices" questionnaire, each question having four answers, only one being correct. At the end of the assessment phase it displays the results.

The application generates a "diploma" that contains the result of the evaluation and the name of the user inserted from a virtual keyboard. This diploma can be locally printed or can be sent to an email address that is entered from the keyboard. If the computer is equipped accordingly with a web camera the application can make a photo capture and after accepting the quality, a photo of the person is included in the diploma. A partial programming code of the self assessment section editor it is presented in Fig. 2 and the self assessment algorithm in Fig. 3.

$-<$ question $><$ text language $=$ "ROM" $>$ Canalul 13 VHF este folosit pentru: $</$ text $>$

$<$ text language $=$ "ENG" $>$ The usage of VHF channel 13 is: $</$ text $>$

$-<$ answer istrue $=" \mathrm{NO} ">$

$<$ text language="ROM">Comunicatii navă-navă de distress $</$ text $>$ 
$</$ answer $>$

$<$ text language $=" E N G ">$ Ship to ship distress communication $</$ text $>$

$-<$ answer istrue $=" \mathrm{NO} ">$

$<$ text language="ROM">Comunicatii navă-navă de urgenţă $</$ text $>$

$<$ text language $="$ ENG" $>$ Ship to ship urgency communication $</$ text $>$

$</$ answer $>$

$-<$ answer istrue $=" \mathrm{NO} ">$

$<$ text language="ROM" $>$ Comunicatii navă-navă de rutină $</$ text $>$

$<$ text language $="$ ENG" $>$ Ship to ship routine communication $</$ text $>$

$</$ answer $>$

$-<$ answer istrue $=" Y E S ">$

$<$ text language="ROM">Comunicatii navă-navă pentru $\mathrm{MSI}</$ text $>$

$<$ text language="ENG" $>$ Ship to ship communication for $\mathrm{MSI}</$ text $>$ $</$ answer $>$

$</$ question $>$

Fig. 2 Editing in Self Assessment Section

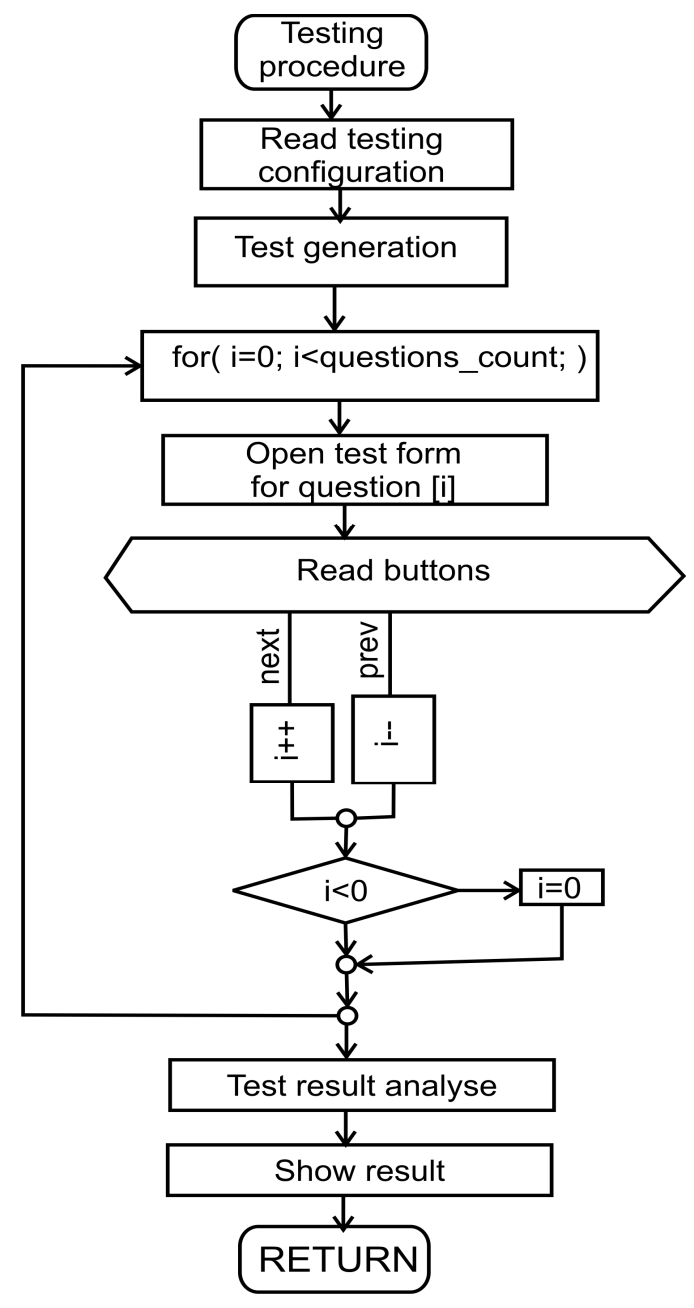

Fig. 3 Algorithm of Self Assessment Section

\section{Results and discussions}

This interactive multimedia application was developed initially in the framework of a co-funded European project [3], has been updated to support training and certification for maritime and inland waterway radio communication and also includes a section for self assessment. 
The syllabus of the GMDSS training course covers a total of 144 hours divided into 64 hours for theory, 72 hours for practical exercises on simulator and real equipments and 8 hours for the final assessment (in case of GOC-General Operator's Certificate Course) [6], [7] .

Through the use of interactive applications, some modules, both theoretical and familiarization with real or simulated equipments, may shorten the course duration by running the application in a classroom equipped with multimedia computers or through self-study before the start up of the course. Applied experimentally on the introductory module - overview of the GMDSS system - it has reduced duration of theory modules by 8-10 hours and duration of practical exercises by 2-4 hours. We estimate what adaptation of further content onto other modules, we could achieve a reduction of about $20 \%$ which would reduce costs accordingly. The duration for running and learning the actual version, validated by completing the evaluation test included, is somewhere around 2 hours.

The application can be easily adapted, without special programming knowledge, so it could extend its use to other programmes. An earlier version of the application runs on InfoDanube [8], the Information and Training and Centre for Inland Waterways Transport, created in the NELI project and further developed in the HINT project.

\section{Conclussions}

Lifelong learning is both a consequence of macro-social dynamics, but also its premise. The contents of different forms of training that a person goes through during life respond less or more to the real needs they have been generated by. In this context adaptation of contents imposes itself as a continuous and flexible process - a defining feature of the learning material.

The AMI Learning application used as an aid in the process of training for radio communication facilitates the assimilation of theoretical knowledge before using the simulator and reduces the duration of training.

The application allows easy updating of information and its subsequent modification to cover the whole area of the theoretical information and self-assessment. Appropriate adaptation of the content for more modules could reduce duration of training up to $20 \%$ in comparison with face to face traditional training. Used as an additional tool it demonstrates how an interactive platform supports the practical training to achieve the required competences for the radio operator job.

Integrating several ways of presenting the information, the application contains photo section, video section, html pages, text section, glossary, links to other resources available on the Internet and self-assessment section. AMI Learning is an attractive and efficient solution compared to the classic PowerPoint widely used in the traditional education. It contains all elements for an interactive multimedia application: multiple media, user control over the delivery of learning material (when, where, how much) and interactivity. In the context of competence based training, where learning becomes a more individualized process, more personal oriented and self managed AMI Learning could be a less expensive solution complementing the more expensive and low flexible software applications or simulators existing on the international market today.

Such an application should be continuously improved both in terms of content and design and although it cannot replace more sophisticated applications or existing simulators, it offers however the trainer the opportunity to organize and continuously adapt the learning material, according to the evolution of topics and feedback received from trainees.

\section{References}

[1] Information on http://www.imo.org .

[2] ITU, Manual for Use by the Maritime Mobile and Maritime Mobile-Satellite Services (Maritime Manual), Edition of 2013, Geneve, 2013, ISBN: 978-92-61-14341-1.

[3] Information on http://www.neliproject.eu ; EU cofounded project, SEE/A/223/3.2/X. 
[4] Information on http://www.hintproject.net ; EU cofounded project, SEE/D/0080/3.2/X.

[5] V. Pipirigeanu: An Analyzing Attempt of Software Applications for Maritime Radiocommunication. In The 6th GMDSS International Conference, Kiev/ Ukraine Odessa National Maritime Academy, (2005)

[6] V. Pipirigeanu., M. Udrea, Introducere în GMDSS-Sistemul Mondial de Primejdie și Siguranţă Maritimă, EUROPOLIS, ISBN 973-8283-54-X , Constanta, 2002.

[7] V. Pipirigeanu, GMDSS Global Maritime Distress and Safety System, CERONAV, ISBN 978606-93369-4-6, Constanta, 2013.

[8] Information on http://www.infodanube.ro. 